\title{
Unilateral and Ipsilateral Strength Asymmetries in Elite Youth Soccer Players With Respect to Muscle Group and Limb Dominance
}

\author{
Asimetría de Fuerzas Unilateral e Ipsilateral en Jugadores de Fútbol de Elite \\ Juveniles con Respecto al Grupo Muscular y a la Dominancia de Miembros
}

Tomas Maly*; Frantisek Zahalka* \& Lucia Mala*

MALY, T.; ZAHALKA, F. \& MALA, L. Unilateral and ipsilateral strength asymmetries in elite youth soccer players with respect to muscle group and limb dominance. Int. J. Morphol., 34(4):1339-1344, 2016.

SUMMARY: The purpose of study was to identify the presence of strength asymmetries (SA) in young elite soccer players in relation to muscle group (knee extensors (KE) and flexors (KF)) and limb preference (dominant vs. non-dominant limb). Forty-one U16 national team soccer players (mean age $15.7 \pm 0.3$ years, body height $177.9 \pm 6.6 \mathrm{~cm}$, body weight $68.2 \pm 7.9 \mathrm{~kg}$ ) participated in this study. Assessments were performed on a Cybex Humac Norm isokinetic dynamometer in concentric contraction. We noted the degree of SAs in the bilateral ratio of quadriceps and hamstrings and in the ipsilateral ratio of the dominant (DL) and non-dominant (NL) legs. Bilateral deficits of KFs were higher (9.02-12.61\%) than those of KFs $(6.32-7.15 \%)$. The percentage of SA (>10 \%) in knee extensors was $19.5-$ $31.7 \%$. The percentage of SA $(>10 \%)$ in knee flexors was 36.6-51.2\%. At the lowest velocity, there was a significantly higher prevalence of SAs in KFs than in KEs $\left(\chi^{2}=4.11, \mathrm{p}<.05\right)$. The ipsilateral ratio was lowest at the lowest velocity regardless of limb dominance (DL: 58.95-63.27 \%, NL: 56.58-60.11\%). At each velocity, the percentage of SA was higher for the non-dominant limb (12.2-24.4\%) than for the dominant one (4.9-14.6\%). Despite these differences, we did not find any significantly higher prevalence of SA in the nondominant limb than in the dominant one $\left(\chi^{2}=.35-2.04, p>.05\right)$. The results of the study suggest that more than $73.2 \%$ of players have at least one SA. More attention should be paid to knee flexors, where a higher percentage of strength asymmetries were observed; furthermore, a higher percentage of strength asymmetry was seen in the non-dominant lower limb.

KEY WORDS: Muscular strength; Strength Asymmetries; Isokinetic testing; Soccer; Injury prevention.

\section{INTRODUCTION}

The positive effects of physical activity (PA) are well known and have been described in the scientific literature. However, both excessive and insufficient PA can negatively impact some aspects of physical fitness in the form of maladaptive effects. If these movement apparatus problems are not compensated for starting in young people (especially in the young sporting population), they can have a negative impact on the child's further development. Negative effects can also be observed in muscle strength differences between more and less preferred muscle groups. A different type of strength asymmetry between the dominant and non-dominant sides or left and right sides has often been studied (Fousekis et al., 2010). The results of some studies indicated that longterm participation in soccer leads to the development of various degrees and modes of functional asymmetry (Fousekis et al.). Limb preference in soccer may lead to strength asymmetries (SA), which may result in large changes in the myodynamic characteristics of the muscle, particularly in the dominant leg. Long-term asymmetrical loading was found to lead to differences in bone mineral composition and density between the dominant and nondominant arms of racquet players (Kannus et al., 1995). Arm asymmetry was also observed in professional tennis players, with approximately $20 \%$ more bone mineral content and muscle mass in the dominant arm (Calbet et al., 1998). Xaverova et al. (2015), found that a bilateral force deficit is more frequent in adult female handball players compared to junior players, which could be due to long-term unilateral orientation of handball-specific skills. Strength asymmetry across the body has been shown to be linked to increased prevalence of injury (McCall et al., 2014) and impaired performance in athletes (Young et al., 2002).

* Charles University in Prague, Faculty of Physical Education and Sport, Czech Republic.

This research was supported by GACR 16-21791S, PRVOUK P38 
Strength is an important component of specific physical fitness in soccer. Testing of lower limb strength is very important because muscle groups (quadriceps, hamstrings and calves) must generate and absorb high forces during acceleration, deceleration, jumping, kicking, turning, tackling, changes of direction and other movement activities during a soccer match. Because the game of soccer frequently involves one-sided activities such as kicking, tackling and passing, asymmetries in muscle strength between both legs are possible.

Long-term preferred and uncompensated loads on one side of the body may lead to asymmetry and dominance of one leg, which can be a result of pre-existing limb preference (footedness). Morgan \& Oberlander (2001) suggested that approximately $75 \%$ of injuries in soccer occur to the lower limbs. A high ratio of hamstring and quadriceps muscle strength is predictive of an increased risk for injury (Fousekis et al.).

The purpose of this study was to identify the presence of strength asymmetries in young elite soccer players in relation to muscle group (knee extensors and flexors) and limb preference (dominant vs. non-dominant limb).

We hypothesized that there would be a significantly higher percentage of strength asymmetries in knee flexors than in knee extensors. We also assumed a higher percentage of strength asymmetries in the ipsilateral ratio (Hamstring to Quadriceps ratio) on the non-dominant limb than in the dominant one.

\section{MATERIAL AND METHOD}

Subject. Forty-one U16 national team soccer players (mean age $15.7 \pm 0.3$ years, body height $177.9 \pm 6.6 \mathrm{~cm}$ and body weight $68.2 \pm 7.9 \mathrm{~kg}$ ) participated in this study between 2011 and 2012. Testing was carried out within a season period at a national camp. Participants recruited were not injured or rehabilitating from an injury at the time of testing. The participants were informed about the measurement procedures and they signed an informed consent form.

Assessment of strength indicators. The muscular strength of the lower limbs was assessed using a Cybex Humac Norm isokinetic dynamometer (Cybex NORM ${ }^{\circledR}$, Humac, CA, USA). The device is hydraulically directed and fully computer controlled in the continuous passive movement, isometric, isotonic and isokinetic concentric and eccentric modes. We tested maximum peak voluntary muscle torque of knee extensors $\left(\mathrm{PT}_{\mathrm{E}}\right)$ and flexors $\left(\mathrm{PT}_{\mathrm{F}}\right)$ on both legs, and based on these values, we derived the ipsilateral ratio of muscle torque for both dominant and non-dominant legs $\left(H: Q_{D}\right.$ and $H: Q_{N}$, respectively) and the bilateral ratio between the exerted strength of knee extensors $(\mathrm{Q}: \mathrm{Q})$ and flexors $(\mathrm{H}: \mathrm{H})$. Strength parameters were obtained in the concentric contraction at angular velocities of $60,120,180,240$ and $300^{\circ} \cdot \mathrm{s}^{-1}$. The maximum peak muscle torque of the knee extensors and flexors of the dominant and non-dominant legs during concentric contraction was measured at five angular velocities of movement $\left(60,120,180240\right.$ and $\left.300^{\circ} \cdot \mathrm{s}^{-1}\right)$. Before measurement, all tested subjects completed a short warm-up (dynamic half squats: 3 sets of 10 repetitions; forward lunges: 3 sets of 10 repetitions) and static stretching of the lower limb muscles (6 minutes) using an individual approach. The testing protocol consisted of three attempts at knee flexion and extension at the monitored velocities (from the lowest to the highest velocity). Before testing at each velocity, the participants completed four training trials at submaximal intensity. Visual feedback and verbal stimulation were given during the testing.

Statistical analysis. From methods of descriptive statistics, we used the mean as a measure of central tendency and standard deviation and standard error of the mean as measures of variability. Data are expressed as mean \pm standard deviation. For statistical analysis, we used the analysis of frequencies and the non-parametric $\chi^{2}$ (chi square distribution) test. The rejection of the null hypothesis was assessed at the level of $\mathrm{p} \leq .05$. Statistical analysis was performed using IBM ${ }^{\circledast}$ SPSS $^{\circledR}$ v21 (Statistical Package for Social Science, Inc., Chicago, IL, 2012).

\section{RESULTS}

The bilateral deficit in knee flexors was higher $(9.02$ $12.61 \%)$ than in knee extensors $(6.32-7.15 \%)$. The percentage of strength asymmetry in knee extensors (BD>10 \%) was 19.5-31.7\% among all tested players depending on angular velocity. The bilateral deficit of knee extensors was higher at lower velocities $\left(60,120^{\circ} \cdot \mathrm{s}^{-1}\right)$ in comparison with higher angular velocities $\left(180-300^{\circ} \cdot \mathrm{s}^{-1}\right)$. The bilateral deficit of knee flexors was higher at the lowest velocity $\left(60^{\circ} \cdot \mathrm{s}^{-1}\right)$ as well as at the highest velocity (300 $\left.{ }^{\circ} \cdot \mathrm{s}^{-1}\right)$. The percentage of strength asymmetry in knee flexors (BD>10\%) was 36.6-51.2\% among all tested players depending on angular velocity. At the lowest velocity, where the players produced the highest peak torques, we found a significantly higher prevalence of strength asymmetry than in knee extensors $\left(\chi^{2}=4.11, \mathrm{p}<.05\right)$ (Table I). At other contraction velocities, the percentage proportion of strength asymmetry was higher in knee flexors; however, 
the prevalence of strength asymmetry in knee flexors did not significantly differ from that in knee extensors.

The ipsilateral ratio (H:Q ratio) was lowest at the lowest velocity regardless of limb dominance (Table II). This ratio on the dominant limb achieved the values of 58.95-63.27\% depending on the movement velocity; values for the non-dominant limb amounted to 56.58$60.11 \%$. At each velocity, the percentage of strength asymmetry was higher for the non-dominant limb (12.2-
$24.4 \%)$ than for the dominant one (4.9-14.6\%). Regardless of limb dominance, the highest prevalence of strength asymmetries was found at "tailed" velocities (60 and $300^{\circ} \cdot \mathrm{s}^{-1}$ ). Despite these differences, we did not find any significantly higher prevalence of strength asymmetry in the non-dominant limb compared to the dominant limb $\left(\chi^{2}=.35-2.04, p>.05\right)$.

Individual assessments showed that in 30 players $(73.2 \%)$, at least one strength asymmetry was identified.

Table I. Bilateral deficit of knee extensors (Q:Q) and flexors $(\mathrm{H}: \mathrm{H})$ and percentage proportion of strength asymmetry in the monitored players. The data are expressed as the mean (standard deviation).

\begin{tabular}{|c|c|c|c|c|c|c|c|c|}
\hline \multirow{7}{*}{$\begin{array}{l}\text { BILATERAL } \\
\text { DEFICIT }\end{array}$} & \multirow{2}{*}{$\begin{array}{c}\text { Angular velocity } \\
\left({ }^{\circ} \cdot \mathbf{s}^{-1}\right)\end{array}$} & \multicolumn{2}{|c|}{ Knee extensors } & \multicolumn{2}{|c|}{ Knee flexors } & \multirow{2}{*}{$\begin{array}{c}\text { Total SA } \\
(\%)\end{array}$} & \multirow{2}{*}{$x^{2}$} & \multirow[b]{2}{*}{$\mathbf{p}$} \\
\hline & & Q:Q ratio & SA (\%) & H:H ratio & SA (\%) & & & \\
\hline & 60 & $6.53(4.89)$ & 29.3 & $10.98(7.61)$ & 51.2 & 40.2 & 4.11 & $\mathrm{p}<.05$ \\
\hline & 120 & $7.15(4.54)$ & 31.7 & $9.02(6.86)$ & 36.6 & 34.1 & 0.22 & $\mathrm{p}>.05$ \\
\hline & 180 & $6.32(4.47$ & 26.8 & $10.51(9.60)$ & 36.6 & 31.7 & 0.9 & $\mathrm{p}>.05$ \\
\hline & 240 & $6.37(5.73)$ & 26.8 & $10.78(9.98)$ & 34.1 & 30.5 & 0.52 & $\mathrm{p}>.05$ \\
\hline & 300 & $6.49(5.83)$ & 19.5 & $12.61(9.76)$ & 41.5 & 30.5 & 4.66 & $\mathrm{p}<.05$ \\
\hline
\end{tabular}

Q-quadriceps, H-hamstring, SA-Strength asymmetry, $\chi^{2}$-chi square statistic, p-probability of rejection of null hypothesis

Table II. Ipsilateral deficit of the dominant and non-dominant legs (H:Q) and percentage proportion of strength asymmetries in the tested players. The data are expressed as the mean (standard deviation).

\begin{tabular}{|c|c|c|c|c|c|c|c|c|}
\hline \multirow[b]{3}{*}{ IPSILATERAL } & \multirow{2}{*}{$\begin{array}{c}\text { Angular } \\
\text { velocity }\left({ }^{\circ} \cdot \mathbf{s}^{1}{ }^{1}\right)\end{array}$} & \multicolumn{2}{|c|}{ Dominant leg } & \multicolumn{2}{|c|}{ Non-dominant leg } & \multirow{2}{*}{$\begin{array}{c}\text { Total SA } \\
(\%)\end{array}$} & \multirow{2}{*}{$x_{2}$} & \multirow{2}{*}{$\mathbf{p}$} \\
\hline & & HQ & SA (\%) & HQ & SA (\%) & & & \\
\hline & 60 & $58.95(8.38)$ & 12.2 & $56.58(8.31)$ & 24.4 & 18.3 & 2.04 & $\mathrm{p}>.05$ \\
\hline \multirow{4}{*}{ DEFICIT } & 120 & $62.22(8.45)$ & 4.9 & $59.43(8.85)$ & 12.2 & 8.5 & 1.41 & $\mathrm{p}>.05$ \\
\hline & 180 & $63.27(8.74)$ & 4.9 & $60.39(10.05)$ & 14.6 & 9.8 & 2.22 & $\mathrm{p}>.05$ \\
\hline & 240 & $62.78(10.21)$ & 12.2 & $59.87(10.87)$ & 17.1 & 14.6 & 0.39 & $\mathrm{p}>.05$ \\
\hline & 300 & $62.63(12.46)$ & 14.6 & $60.11(12.87)$ & 19.5 & 17.1 & 0.35 & $\mathrm{p}>.05$ \\
\hline
\end{tabular}

Q-quadriceps, H-hamstring, SA-Strength asymmetry, $\chi^{2}$-chi square statistic, p-probability of rejection of null hypothesis.

\section{DISCUSSION}

Strength is an important component of specific physical fitness in soccer. Testing of lower limb strength is important because muscle groups (quadriceps, hamstring, and calves) must generate and absorb high forces during acceleration, deceleration, jumping, kicking, turning, tackling, changes of direction and other movement activities during soccer matches.

Bilateral deficit. The results of our study revealed higher values of bilateral deficit in knee flexors compared to extensors at all monitored velocities based on their prevalence (Table I). The average values of the bilateral deficit of knee extensors $(6.53 \pm 4.89 \%)$ and knee flexors $(10.98 \pm 7.61 \%)$. at the lowest velocity were not consistent with the results of the study of Carvalhais et al. (2013), who reported in professional Brazilian players $(\mathrm{n}=164)$ a knee extensor strength asymmetry of $7.75 \%$ and knee flexor asymmetry of $8.10 \%$. Maly et al. (2015a) reported a bilateral deficit in knee extensors of $7.24 \pm 4.21 \%$ and $10.18 \pm 8.66$ $\%$ in knee flexors in elite female soccer players. The percentage of strength asymmetry in knee extensors (BD>10 $\%$ ) was $19.5-31.7 \%$ among all tested players depending on angular velocity. The bilateral deficit of knee extensors was higher at lower velocities $\left(60,120^{\circ} \cdot \mathrm{s}^{-1}\right)$ compared to higher angular velocities $\left(180-300^{\circ} \cdot \mathrm{s}^{-1}\right)$. The bilateral deficit of knee flexors was higher at the lowest velocity $\left(60^{\circ} \cdot \mathrm{s}^{-1}\right)$ as well as at the highest velocity $\left(300^{\circ} \cdot \mathrm{s}^{-1}\right)$. The highest values of strength asymmetry at the highest velocities were also published in other studies (Maly et al., 2015b). Because hamstring injury is the most common injury in football and 
most of the hamstring injuries occur to the biceps femoris, more attention should be paid to knee flexors (Ekstrand et al., 2012). At the lowest velocity $\left(60^{\circ} \cdot \mathrm{s}^{-1}\right)$, more than $51 \%$ of players have bilateral knee flexor strength deficits higher than $10 \%$. Moreover, at the lowest velocity, where the players produced the highest peak torques, we found a significantly higher prevalence of strength asymmetry than in knee extensors $\left(\chi^{2}=4.11, \mathrm{p}<.05\right)$ (Table I). This finding does not correspond with the study of Daneshjoo et al. (2013), who reported in youth elite players ( $n=36$, age $18.9 \pm 1.4$ years) an insignificant difference in the prevalence of bilateral deficit of knee extensors and flexors. Significant differences between the dominant and non-dominant limbs during concentric contraction at a velocity of $60^{\circ} \cdot \mathrm{s}^{-1}$ in adult elite athletes $(\mathrm{Q}: \mathrm{Q}=$ $10.53 \pm 9.44 \%, \mathrm{H}: \mathrm{H}=10.30 \pm 5.69 \%$ ) were published by Jones \& Bampouras (2010). Rahnama et al. (2005), suggested that up to $68 \%$ of soccer players had muscle asymmetries in extensors or flexors between the extremities of higher than 10 $\%$ in at least one of the measurements of muscle strength. Muscle bilateral asymmetries were found in at least one measurement in $50 \%$ of players at a velocity of $60^{\circ} \cdot \mathrm{s}^{-1}$ and in $75 \%$ of players at a velocity of $300^{\circ} \cdot \mathrm{s}^{-1}$ (Maly et al., 2010).

At the highest velocity $\left(300^{\circ} \cdot \mathrm{s}^{-1}\right)$, more than $41 \%$ of the players have bilateral force deficits of knee flexors higher than $10 \%$. Daneshjoo et al., reported a higher percentage of bilateral force deficits of both knee flexors (58.3-72.2\%) and knee extensors (44.4-52.8\%).The observed asymmetry at higher angular velocities deserves increased attention because the key specific activities (shooting, jumping, sprinting, acceleration, deceleration of movement, changes of direction speed, long distance passing, etc.) are performed at high velocities.

Our results are similar to the study of Lehance et al. (2009), who measured the muscle strength of elite and subelite soccer players $(n=57)$ on an isokinetic dynamometer during the preparatory period and found out that up to $56 \%$ of players are at risk for muscle strength asymmetry of the knee flexors or extensors. The authors reported a higher proportion of muscle strength asymmetry in young soccer players than in senior players. Knapik et al. (1991), reported that athletes with muscle strength imbalances higher than $15 \%$ at a bilateral comparison of extremities had a 2.6-times higher frequency of injuries when compared to athletes for whom this difference was lower than $15 \%$. In the training process, these strength characteristics should be detected and compensated for using an individual strength program. In our study, the percentage of strength asymmetry (BD>10 \%) in knee extensors and flexors was lower than in older elite players (Daneshjoo et al.). This result can be attributed to the fact that our players are, as members of the Czech national team, regularly monitored and the results of testing are sent to clubs in order to compensate for the observed strength asymmetries. Muscle imbalance higher than $10 \%$ of deficit indicates a potential risk for players, predisposing them to possible muscle-related injuries such as strains and tendinitis (Davies et al., 2000).

Ipsilateral asymmetries. Ipsilateral asymmetry (H:Q ratio) reflects the percentage proportion of peak torque of agonist and antagonist muscle groups of the same limb. H:Q is an indicator of the functional ability of muscle groups around the knee joint as a performance criterion. This ratio is difficult to generalize; however, some studies report its magnitude in the range of 50 to $80 \%$ depending on knee angle and angular velocity (Zabka et al., 2011). At lower velocities (60-180 ${ }^{\circ} \cdot \mathrm{s}^{-}$ $\left.{ }^{1}\right)$, the agonist/antagonist ratio should be approximately 60 $\%$. Hoffman et al. (1992), reported that $6: 10$ is a normal H:Q ratio. In our study, the ipsilateral ratio (H:Q ratio) was lowest at the lowest velocity regardless of limb dominance. This ratio on the dominant limb achieved values of 58.95-63.27\% depending on the movement velocity; values for the nondominant limb amounted to 56.58-60.11\%. These results are consistent with the study of Gür et al. (1999), who reported in elite players $\mathrm{H}: \mathrm{Q}$ ratio values of $56-63 \%$ for the dominant leg and 55-61\% for the non-dominant leg. Compared to Daneshjoo et al., findings, our players generated higher values of $\mathrm{H}$ :Q ratio at the velocity of $60^{\circ} \cdot \mathrm{s}^{-1}$ (for both dominant and non-dominant legs) and lower values at the velocity of 300 ${ }^{\circ} \cdot \mathrm{s}^{-1}$. Similarly, at the lowest velocity $\left(60^{\circ} \cdot \mathrm{s}^{-1}\right)$, our players produced comparable values with professional adult players and lower values $(\sim 9 \%)$ at the velocity of $300^{\circ} \cdot \mathrm{s}^{-1}$ (Fousekis et al.). A higher $\mathrm{H}: \mathrm{Q}$ ratio at $300^{\circ} \cdot \mathrm{s}^{-1}$ was also reported in other studies (Lehance et al.; Maly et al., 2010). Based on the aforementioned studies, it is possible to increase the H:Q ratio for the dominant and non-dominant legs using specific interventions, especially at higher movement velocities.

At each velocity, the percentage of strength asymmetry was higher for the non-dominant limb (12.2-24.4\%) than the dominant one (4.9-14.6\%). Regardless of limb dominance, the highest percentage of strength asymmetries was found at "tailed" velocities $\left(60\right.$ and $\left.300^{\circ} \cdot \mathrm{s}^{-1}\right)$. Despite the mentioned differences, we did not find any significantly higher prevalence of strength asymmetry on the non-dominant limb than on the dominant limb $\left(\chi^{2}=.35-2.04, \mathrm{p}>.05\right)$. A higher $\mathrm{H}$ : $\mathrm{Q}$ ratio in favour of the dominant limb may be due to the more frequent use of that leg for kicking, when the knee flexors have to decelerate the lower leg during kicking and passing a ball, which causes better adaptation of the particular muscle groups. Sixteen players $(61 \%)$ had at least at one of the tested angular velocities, ipsilateral ratio (H:Q) lower than $50 \%$. Values below $50 \%$ indicate a severe level of muscular imbalance (Zabka et al.). These data reflect a discrepancy between the muscle strength of knee extensors and flexors. When the extensors exert substantially larger forces than the flexors, 
excessive anterior translation of the tibia on the femur may occur during dynamic activities, and the anterior cruciate ligament (ACL) will experience higher-than-normal shear forces, mainly in the final knee extension angles and during intense quadriceps contractions (Magalhães et al., 2004). If the flexors are too weak to counteract this force, the ACL may be injured (Cheung et al., 2012).

There are some limitations of our study. First, our data are representative of only one age category (U16) and the top sport level (members of the national team). Second, the ipsilateral $\mathrm{H}: \mathrm{Q}$ ratio was obtained from concentric contraction (conventional ratio). The Eccentric hamstring to concentric quadriceps (functional ratio) may be a better method of simulating the co-activation pattern developed in the leg deceleration phase during the final stage of knee extension.

In conclusion, our study found that more than $73.2 \%$ of players have at least one strength asymmetry. More attention should be paid to knee flexors where we found strength asymmetry in $51.2 \%$ of the tested players at the lowest velocity and in $41.5 \%$ at the highest velocity. The non-dominant limb also deserves increased attention because its ipsilateral ratio was lower at each velocity compared to the dominant limb and strength asymmetries also achieved a higher percentage proportion. Maladaptive effects of body strength asymmetries represent a potential risk of injury; therefore, the observed asymmetries should be systematically monitored and compensated for using specific exercises. Further research should focus on the changes in strength asymmetries under fatigue (after specific physical load), their monitoring during the season (seasonal variability), from the perspective of field position, the efficiency of their compensation and, in particular, their early diagnostics, detection and identification of their causes (analysis of the training load structure and extracurricular unilateral physical activities, e.g., skateboard, snowboard, scooter).

Precise determination and quantification of muscle strength imbalances is essential for determining the fundamental level of organized and intentionally controlled training and for early compensation for the observed imbalances to protect against potential injury. In terms of practice, the results may be beneficial for fitness coaches, physiotherapists, doctors and other clinical staff in professional soccer.

\section{ACKNOWLEDGEMENTS}

This research was supported by GACR 16-21791S, PRVOUK P38

MALY, T.; ZAHALKA, F. \& MALA, L. Asimetría de fuerzas unilateral e ipsilateral en jugadores de fútbol de elite juveniles con respecto al grupo muscular y a la dominancia de miembros. Int. J. Morphol., 34(4):1339-1344, 2016.

RESUMEN: El objetivo de este estudio fue identificar la presencia de asimetría de fuerzas (AF) en jóvenes jugadores de fútbol de élite en relación con el grupo de músculos extensores de la rodilla (ER) y flexores (FR) y la preferencia de los miembros (miembro dominante frente al miembro no dominante). Participaron en este estudio 41 jugadores sub-16 del equipo nacional de fútbol (edad media

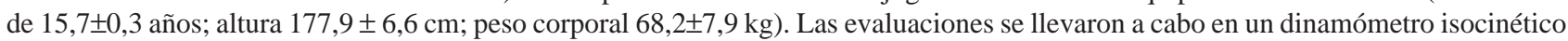
Cybex Humac Norm en contracción concéntrica. Se registró el grado de AF en la relación bilateral de los músculos cuádriceps y los tendones y en la relación ipsilateral del miembro dominante (MD) y el miembro no dominante (MND). Los déficits bilaterales fueron más altos en FR $(9,02$ a 12,61 \%) que en ER $(6,32-7,15 \%)$. El porcentaje de $\mathrm{AF}$ (> $10 \%)$ en los músculos extensores de la rodilla fue de 19,5 a $31,7 \%$. El porcentaje de AF (> $10 \%$ ) en los músculos flexores de la rodilla fue de 36,6 a 51,2 \%. A la velocidad más baja, había una mayor prevalencia de AF en FR que en ER $\left(\chi^{2}=4.11, \mathrm{p}<0,05\right)$. La relación ipsilateral fue la más baja a la velocidad más baja, independientemente de la dominancia de los miembros (MD: 58,95 a 63,27 \%, MND: 56, 58-60, $11 \%$ ). En cada velocidad, el porcentaje de AF fue mayor para el miembro no dominante (12,2 a 24,4\%) que para el miembro dominante (4,9 a 14,6 \%). A pesar de estas diferencias, no hemos encontrado ningún prevalencia significativamente mayor de AF en el miembro no dominante en comparación al miembro dominante $\left(\chi^{2}=0,35\right.$ a 2,04, p > 0,05). Los resultados del estudio sugieren que más de 73,2 \% de los jugadores tienen al menos una AF. Más se debe prestar atención a los músculos flexores de la rodilla, donde se observó un mayor porcentaje de asimetría de fuerzas. Por otra parte, un mayor porcentaje de asimetría de fuerzas se observó en el miembro inferior no dominante.

PALABRAS CLAVE: Fuerza muscular; Asimetría de fuerzas; Evaluación isocinética; Fútbol; Prevención de lesiones.

\section{REFERENCES}

Calbet, J. A.; Moysi, J. S.; Dorado, C. \& Rodríguez, L. P. Bone mineral content and density in professional tennis players. Calcif. Tissue Int., 62(6):491-6, 1998.
Carvalhais, V. O. C.; dos Santos, T. R. T.; Araújo, V. L.; Leite, D. X.; Dias, J. M. D. \& da Fonseca, S. T. Muscular strength and fatifue index of knee extensors and flexors of professional 
soccer players according to their positioning in field. Rev. Bras. Med. Esporte, 19(6):452-56, 2013.

Cheung, R. T. H.; Smith, A. W. \& Wong, D. P. H:q ratios and bilateral leg strength in college field and court sports players. $J$. Hum. Kinet., 33:63-71, 2012.

Daneshjoo, A.; Rahnama, N.; Mokhtar, A. H. \& Yusof, A. Bilateral and unilateral asymmetries of isokinetic strength and flexibility in male young professional soccer players. J. Hum. Kinet., 36:45-53, 2013.

Davies, G. J.; Heiderscheit, B. \& Brinks, K. Test Interpretation. In: Brown, L. E. (Ed.). Isokinetics in Human Performance. Champaign, Human Kinetics, 2000. pp.3-25.

Ekstrand, J.; Healy, J. C.; Waldén, M.; Lee, J. C.; English, B. \& Hägglund, M. Hamstring muscle injuries in professional football: the correlation of MRI findings with return to play. Br. J. Sports Med., 46(2):112-7, 2012.

Fousekis, K.; Tsepis, E. \& Vagenas, G. Lower limb strength in professional soccer players: profile, asymmetry, and training age. J. Sports Sci. Med., 9(3):364-73, 2010.

Gür, H.; Akova, B.; Pündük, Z. \& Küçükoglu, S. Effects of age on the reciprocal peak torque ratios during knee muscle contractions in elite soccer players. Scand. J. Med. Sci. Sports, 9(2):81-7, 1999.

Hoffman, J. R.; Maresh, C. M. \& Armstrong, L. E. Isokinetic and dynamic constant resistance strength testing: Implication for sport. Phys. Ther. Pract., 2:42-53:1992.

Jones, P. A. \& Bampouras, T. M. A comparison of isokinetic and functional methods of assessing bilateral strength imbalance. J. Strength Cond. Res., 24(6):1553-8, 2010.

Kannus, P.; Haapasalo, H.; Sankelo, M.; Sievänen, H.; Pasanen, M.; Heinonen, A.; Oja, P. \& Vuori, I. Effect of starting age of physical activity on bone mass in the dominant arm of tennis and squash players. Ann. Intern. Med., 123(1):27-31, 1995.

Knapik, J. J.; Bauman, C. L.; Jones, B. H.; Harris, J. M. \& Vaughan, L. Preseason strength and flexibility imbalances associated with athletic injuries in female collegiate athletes. Am. J. Sports Med., 19(1):76-81, 1991.

Lehance, C.; Binet, J.; Bury, T. \& Croisier, J. L. Muscular strength, functional performances and injury risk in professional and junior elite soccer players. Scand. J. Med. Sci. Sports, 19(2):243-51, 2009.

Magalhães, J.; Oliveira, J.; Ascensão, A. \& Soares, J. Concentric quadriceps and hamstrings isokinetic strength in volleyball and soccer players. J. Sports Med. Phys. Fitness, 44(2):119-25, 2004.
Maly, T.; Zahalka, F.; Bonacin, D.; Mala, L. \& Bujnovsky, D. Muscular strength and strength asymmetries of high elite female soccer players. Sport Sci., 8(Suppl. 1):7-14, 2015 a.

Maly, T.; Zahalka, F. \& Mala, L. Isokinetic strength, ipsilateral and bilateral ratio of peak muscle torque in knee flexors and extensors in elite young soccer players. Acta Kinesiol., 4(2):1723, 2010.

Maly, T.; Zahalka, F.; Mala, L. \& Cech, P. The bilateral strength and power asymmetries in untrained boys. Open Med., 10(1):224-32, 2015b.

McCall, A.; Carling, C.; Nedelec, M.; Davison, M.; Le Gall, F.; Berthoin, S. \& Dupont, G. Risk factors, testing and preventative strategies for non-contact injuries in professional football: current perceptions and practices of 44 teams from various premier leagues. Br. J. Sports Med., 48(18):1352-7, 2014.

Morgan, B. E. \& Oberlander, M. A. An examination of injuries in major league soccer. The inaugural season. Am. J. Sports Med., 29(4):426-30, 2001.

Rahnama, N.; Lees, A. \& Bambaecichi, E. Comparison of muscle strength and flexibility between the preferred and non-preferred leg in English soccer players. Ergonomics, 48(11-14):1568$75,2005$.

Xaverova, Z.; Dirnberger, J.; Lehnert, M.; Belka, J.; Wagner, H. \& Orechovska, K. Isokinetic strength profile of elite female handball players. J. Hum. Kinet., 49:257-66, 2015.

Young, W. B.; James, R. \& Montgomery, I. Is muscle power related to running speed with changes of direction? J. Sports Med. Phys. Fitness, 42(3):282-8, 2002.

Zabka, F. F.; Valente, H. G. \& Pacheco, A. M. Isokinetic evaluation of knee extensor and flexor muscles in professional soccer players. Rev. Bras. Med. Esporte, 17(3):189-92, 2011.

\author{
Correspondence to: \\ Dr. Tomas Maly \\ Faculty of Physical Education and Sport \\ Charles University in Prague \\ José Martího 31 \\ 16252 Prague \\ CZECH REPUBLIC
}

Email: tomimaly@yahoo.com
Received: 11-06-2016 Accepted: 20-09-2016 